\title{
Categorical Norms and Convention-Relativism about Epistemic Discourse
}

\begin{abstract}
Allan Hazlett has recently developed an alternative to the most popular form of antirealism about epistemic normativity, epistemic expressivism. He calls it "conventionrelativism about epistemic discourse". The view deserves more attention. In this paper, I give it attention in the form of an objection. Specifically, my objection turns on a distinction between inescapable and categorical norms. While I agree with Hazlett that convention-relativism is consistent with inescapable epistemic norms, I argue that it is not consistent with categorical epistemic norms. I then argue that Hazlett's account of a controversial upshot of convention-relativism - namely, that epistemic discourse is not "normative" - should, but does not, adequately address the question of whether epistemic norms are categorical. This leads to a more general discussion of anti-realism in epistemology.
\end{abstract}

\section{Introduction}

Allan Hazlett $(2013 ; 2014)$ has recently developed an alternative to the most popular form of anti-realism about epistemic normativity, epistemic expressivism. He calls it "convention-relativism about epistemic discourse". The view draws on Ernie Sosa's “insulated critical domains” (Sosa 2007). Hazlett combines Sosa’s framework with a view about the conventional nature of epistemology's "central organizing value" and draws some controversial meta-epistemological implications. To my knowledge, it is the only existing attempt at aligning Sosa's framework with an explicitly anti-realist meta-epistemological stance. I think the view deserves more attention. Here I give it attention in the form of an objection. Specifically, my objection turns on a distinction between inescapable and categorical norms. While I agree with Hazlett that conventionrelativism is consistent with inescapable epistemic norms, I argue that it is not consistent with categorical epistemic norms. I then argue that Hazlett's account of a controversial upshot of convention-relativism - namely, that epistemic discourse is not "normative" - 
should, but does not, adequately address the question of whether epistemic norms are categorical. Doing so requires assessing the anti-realist options on this score. In particular, if Hazlett's main anti-realist competitor, epistemic expressivism, can embrace categorical epistemic norms without incurring the disadvantages Hazlett claims it does, then it looks like we can embrace a very natural way of thinking about epistemic discourse while remaining anti-realist. I argue that this is the case, and that, for this reason, more needs to be said about why convention-relativism is an attractive anti-realist alternative.

\section{Convention-Relativism about Epistemic Discourse}

The view's core is Sosa's notion of insulated critical domains. To illustrate, recall Sosa's coffee analogy (Sosa 2007). The basic idea is that evaluations concerning a wide range of items having to do with coffee drinking - coffee bean fields, coffee machines, coffee mugs - are organized by or derivative from a central value, namely "the value of liquid coffee that is delicious and aromatic" (Sosa 2007, p.73). When I evaluate a coffee machine as a good coffee machine, I evaluate it as good relative to the central organizing value of delicious aromatic liquid coffee. Evaluations that are organized by or derivative from this central value comprise the critical domain of coffee drinking. Sosa's idea is that epistemology is a domain of this kind. According to Sosa, epistemology is organized

around the central value of true belief. Positive or negative evaluations of, for example, a belief-forming process, an argument, or a person's method of inquiry are organized by or derivative from the central value of true belief. These evaluations comprise the critical domain of epistemology (“the epistemic domain"). 
To call a critical domain "insulated" is to claim that the central organizing value need not be valued or valuable in order to structure evaluation within the critical domain. For example, on this model, I can truly and sincerely claim that a coffee machine is a "good" coffee machine without this requiring that I value liquid coffee, and without this requiring that liquid coffee is intrinsically valuable. The central organizing value of delicious and aromatic liquid coffee need not be "domain transcendent". It simply has to make sense of evaluations within the critical domain, from a structural or explanatory point of view.

When it comes to epistemology, the basic point is that the question of the structure and nature of epistemic evaluation can be seen as orthogonal to the question of the value of true belief. As Sosa puts it:

Our present worry abstracts from such Platonic issues of epistemic normativity. Truth may or may not be intrinsically valuable absolutely, who knows? Our worry requires only that we consider truth the epistemically fundamental value (Sosa 2007, p.72).

Regardless of whether it is intrinsically valuable (i.e. domain-transcendently valuable) true belief structures, or organizes our evaluations in the epistemic domain. ${ }^{1}$ Again, it makes sense of them, from a structural or explanatory point of view. This of course raises

\footnotetext{
${ }^{1}$ What is the motivation for remaining agnostic on the intrinsic value of true belief? For one thing, cases of trivial truths cast doubt on the idea. Meanwhile, adjusting one's theory of the value of true belief such that cases of trivial truths are not valuable can threaten the scope of epistemic normativity, depending on how one understands the nature of epistemic normativity. A central motivation for Sosa's insulated critical domains is that it provides satisfactory scope for epistemic normativity without claiming that trivial truths are intrinsically valuable (see Grimm 2009).
} 
a question. If not its intrinsic value, what else explains true belief's status as the central organizing value of the epistemic domain?

Hazlett's answer to this question is "convention". That is to say, "what makes one thing, rather than another, the central organizing value of the critical domain of the epistemic is a matter of what we mean by "epistemic"” (Hazlett 2014, p.231). According to Hazlett, "epistemic" is term of art. It is philosophers" jargon (contrast "moral" or "aesthetic"). ${ }^{2}$ Thus, figuring out what "we" mean by "epistemic" is a matter of best capturing or systematizing the practices of the relevant theorists - i.e. the ones who use the term "epistemic" (Hazlett 2013, Ch.9.3; 2014, p.231). In contrast with Sosa, Hazlett claims this job is best done by the notion of accuracy - a more general sort of value, of which true belief is a paradigm case. But that is unimportant for present purposes.

Convention-relativism about epistemic discourse, then, is the view that our epistemic evaluations (thought and talk) are true relative to a non-domain-transcendent central organizing value - namely, the value of accuracy. That this is the case is determined by the conventional facts about what the relevant theorists mean by "epistemic". Commitment to the "insulated" nature of critical domains - and seeing the epistemic as just one more of these - is what makes convention-relativism consistent with anti-realism about epistemic normativity: “Critical domains are 'insulated' and free from commitment to the 'real' existence of the relevant values. To say that true belief [or, more generally, accuracy] is epistemically valuable is not to say anything about the worth

\footnotetext{
${ }^{2}$ Hazlett provides interesting evidence for this claim from the Oxford English Dictionary (Hazlett 2014, p. 231).
} 
of the central organizing value of the critical domain of the epistemic..." (2014, p.234; see also 2013, Ch. 9.2.3). ${ }^{3}$

The view differs from expressivism in the following key way. Very roughly, according to a prominent version of expressivism, a positive epistemic evaluation (such as "S is justified in believing that p") is to be understood as expressing a complex mental state consisting of i) a belief that S's belief that $\mathrm{p}$ conforms to some set of standards, and ii) a non-representational attitude of acceptance towards those standards. ${ }^{4}$ It is a complex issue how exactly to understand the idea of an attitude of acceptance in this context. ${ }^{5}$ However we spell out the details, the main point is that it plays a non-representational organizing role vis-à-vis our beliefs or credences. I will return to this issue below.

Hazlett claims that convention-relativism differs with respect to the second part of the expressivist's semantic set-up. The way he puts the point, an agent can positively epistemically evaluate a belief, an argument, or someone's method of inquiry, without thereby valuing (expressing any attitude of acceptance towards) the central organizing value of the critical domain of the epistemic. While an agent may express a positive or negative non-representational attitude concerning the central organizing value of the

\footnotetext{
${ }^{3}$ Convention-relativism likens the epistemic domain to the rules of a club. The rules of etiquette in the club may be structured around a central organizing value without that thereby implying anything about its worth or value. As I note below, this is not a necessary condition on being consistent with anti-realism. Expressivism is consistent with anti-realism for different reasons.

${ }^{4}$ This is roughly Chrisman (2007). Other prominent epistemic expressivists include Ridge (2007) and Gibbard (2003). Some of them frame the view in importantly different ways. These differences need not concern us for present purposes.

${ }^{5}$ Hazlett seems comfortable equating it with endorsement and approval. As I argue below, I think this is problematic.
} 
epistemic domain, such expressions are not built in to the semantics of epistemic discourse. ${ }^{6}$ As we will see below, Hazlett takes this to be the main advantage of convention-relativism over expressivism.

In sum, the view is an alternative to the most prominent form of metaepistemological anti-realism. It draws on Sosa's insulated critical domains, one of the prominent views in normative epistemology. These features, among others, make it an interesting view that deserves discussion. But convention-relativism has some controversial consequences. As I argue below, it is not clear that Hazlett has the resources to successfully handle them.

\section{Binding Nature of Epistemic Evaluation}

Epistemologists often speak of the "binding" nature of epistemic evaluation (Berker 2013; Grimm 2009; Kelly 2003). When we assess someone’s belief as ungrounded, for example, we in some sense call upon that person to change what they believe, or perhaps to respond with grounds. Moreover, according to many epistemologists, this seems true in a "non-optional" way (Grimm 2009). That is, regardless of whether the person with the ungrounded belief wants to or not (or has any interest whatsoever in what we are after), we still think it is incumbent upon them change their belief (or the situation).

Convention-relativism seems to be at odds with this picture. After all, in grounding the critical domain of epistemology in convention, Hazlett explicitly likens

\footnotetext{
${ }^{6}$ That the speaker need not endorse the central organizing value in making epistemic evaluations also distinguishes convention-relativism from what Boghossian (2006) calls “epistemic relativism".
} 
epistemic norms to the rules of the "Plantation Club". One of the rules of the Plantation Club is that you must only eat peas with a spoon. Surely there is nothing non-optional about obeying such a rule. However, Hazlett draws a distinction that looks relevant here. He distinguishes between "inescapable" and "instrumental" norms. Roughly, inescapable norms apply to you regardless of your goals or desires. Meanwhile, instrumental norms are contingent on your goals or desires. He claims that convention-relativism "is consistent with, and can explain, the fact that epistemic normativity is inescapable, in Philippa Foot's (1972) sense..." (p.234). And indeed, we can see this simply by looking at what has been explained above. Namely we have seen that a critical domain's central organizing value can do the work of structuring and explaining evaluations in that domain without being valued by anyone. This is arguably another way of saying, for example, that a person (or their beliefs) can be evaluated within the critical domain of epistemology regardless of whether they care about having true beliefs. I agree that convention-relativism is consistent with the inescapability of epistemic normativity.

However, we need to draw a further distinction in order to get clear on what epistemologists often mean by "non-optional" or "binding". We need to contrast "inescapability" with a further, stronger, notion of "categoricity".

- Inescapability: a norm $\mathrm{N}$ is inescapable if and only if it applies to you, regardless of your aims or desires. 
- Categoricity: a norm $\mathrm{N}$ is categorical if and only if it gives you a reason to $\Phi$, regardless of your aims or desires. ${ }^{7}$

What does it mean for a norm to give you a reason to $\Phi$ ? First of all, I should emphasize that I have what are often called normative reasons in mind, as opposed to motivating, or explanatory reasons. I should also emphasize that, to make my point, I need merely have pro tanto reasons in mind. I see no reason to think categorical norms necessarily give you something more than a pro tanto reason to $\Phi$. A widely endorsed view is that pro tanto normative reasons are considerations that speak in favour of $\Phi$-ing (Sylvan forthcoming). ${ }^{89}$ To put things somewhat differently, then, we can say: if a categorical norm prescribes $\Phi$-ing, this is a consideration (or, rather, this entails that there are considerations) that speak(s) in favour of $\Phi$-ing, regardless of your aims or desires. Meanwhile, if an inescapable norm prescribes $\Phi$-ing, this need not speak in favour of $\Phi$-ing, regardless of your aims or desires. Inescapable norms merely apply to you, regardless of your aims or desires. To see that a norm can apply to you and yet fail to give you a reason to do

\footnotetext{
${ }^{7}$ This way of drawing the distinction is due to Hazlett (personal communication).

${ }^{8}$ When it comes to normative reasons, there is a widely recognized distinction between reasons there are ("objective reasons") and reasons one has ("subjective reasons"). Consider the classic gin and petrol case. When a crazed bartender serves you a glass of petrol (which is for the moment indistinguishable from gin), there $i s$ a conclusive reason not to drink what's in the glass; but since you cannot tell the difference, the fact there is petrol in the glass is not a reason you have not to drink what's in the glass. That reason is not yet possessed by you. Whether subjective reasons are just a subspecies of objective reasons (the possessed ones), and exactly what reason-possession amounts to, are questions I do not need to get into here. Whether we understand categorical norms in terms of reasons there are or reasons one has does not affect the usefulness of my schema in highlighting the difference between categorical and inescapable norms.

${ }^{9}$ There is also a debate about the ontology of normative reasons. Some think normative reasons are mental states; some think they are facts or apparent facts (usually about the world); still others think they are propositions. I wish to remain neutral on this debate. See (Sylvan forthcoming) for helpful discussion.
} 
anything, consider the Plantation Club's pea and spoon rule: whether or not it applies to you is not a matter of your aims or desires. But it is not categorical: despite applying to you, it need not give you a reason (even a pro tanto one) to do anything independently of your aims or desires.

Convention-relativism is incompatible with categorical epistemic norms. Again, this is because it grounds the critical domain of epistemology in convention. There are countless examples of conventions which - while they may generate inescapable norms do not give you a pro tanto normative reason to do anything, independently of your aims or desires. At the risk of belaboring the obvious, consider these conventions as a case in point:

- Standing ovations at outstanding classical music concerts.

- Kissing one another on the cheek three times as a mark of formality, birthdays, or the return from a long absence.

- "Liking" photos of your friends on Facebook.

More than this, it is implausible that mere conventions ever generate norms that give you a pro tanto normative reason to do anything, independently of your aims or desires. For one thing, conventional norms are a helpful contrast to categorical norms. But more importantly, whatever the conditions on conventionhood (see e.g. Lewis 1969), it does not follow from the mere fact that a large group of people $\Phi$ - in a way that meets the relevant conditions on conventionhood - that one has a pro tanto normative reason to $\Phi$, independently of one's aims or desires. Therefore, because convention-relativism 
grounds the critical domain of epistemology in convention, it is incompatible with categorical epistemic norms.

\section{Reverse Open Question Argument}

Hazlett acknowledges that an important upshot of convention-relativism is that epistemic discourse is "not normative". And he grants that this is of course controversial. He seeks to defend his view by arguing that epistemic discourse is indeed not normative, despite seeming normative. He also provides an explanation as to why it seems normative. I focus here on his argument that epistemic discourse is not normative. Since worries about bindingness got us concerned about the view in the first place, we need to investigate whether Hazlett's argument accounts for such worries.

He calls it the "reverse open question argument". The idea is that if we can coherently ask a question such as "S epistemically ought to believe that $\mathrm{p}$, but ought $\mathrm{S}$ really believe that p?", then "epistemically ought" is not normative. The same goes for epistemic uses of "good" and "virtuous" (Hazlett 2013, Ch. 9.2.3; 2014, p.238). Hazlett claims that we can coherently ask such questions:

We might put our point this way: we can coherently question the normative force of epistemic value (or of epistemic rules or norms). 'Epistemically good' and 'epistemically ought' are different from words like 'good' and 'ought', sans qualification. There is an obvious sense in which it is incoherent to ask whether the good really is good, or whether one really ought to do what one ought to do. This provides at least one sense in which good-talk and ought-talk is normative. But this doesn't apply, mutatis mutandis, to epistemic discourse” (p.239). 
This is suggestive. But it is not entirely clear how to understand the putatively open question. To my mind, the most natural idea here is that we can grant that someone epistemically ought to believe that $p$, and then coherently ask whether it is the case that they ought, all-things-considered, to believe that $p$. But Hazlett denies this: "I do not just mean that the epistemic 'ought' is not the all-things-considered 'ought.' I mean that, even granting that S epistemically (but not all-things-considered) ought to $\Phi$, it is coherent to ask whether S really ought to $\Phi$, i.e. whether $\mathrm{S}$ is really under any kind of obligation to Ф” (2013; p.261). But Hazlett needs to be careful here. After all, in considering a situation in which one epistemically ought to $\Phi$, Hazlett automatically grants that one ought to believe that $p$ in at least one way-i.e. the epistemic way! So it does of course seem incoherent to go on to ask whether S ought to $\Phi$ in any kind of way (or as Hazlett puts it, to be under "any kind of obligation to $\Phi$ "). Indeed, it seems that all the action surrounds what "really" means in the putatively open question. Hazlett should be understood as differentiating the epistemic "ought" from the real "ought", and asking the open question as such. But the notion of the real ought is still unacceptably vague and obscure. We need to be more precise if judgments about coherence are to be taken seriously. ${ }^{10}$

\footnotetext{
${ }^{10}$ One issue here, which I will simply set to one side, is that it seems the more clearly we spell out the putatively open question, the very idea of drawing conclusions on the basis of a coherence test begins to lose cogency. This is because, as will become clear, we seem forced to spell out the putatively open question with rather technical terms (like "pro tanto", and "deliberative"), and it's not clear what we are entitled to infer from our intuitions about the coherence of questions involving such technical terms. For one thing, we might wonder about the status of the intuitions themselves. Insofar as we understand the relevant question, it seems any intuitions about coherence will be tainted by theoretical leanings, for example.
} 
On one interpretation, the idea is that we can grant that someone epistemically ought to believe that $p$, and then coherently ask whether it is the case that they ought, in the sense of having a pro tanto normative reason, to believe that $p .{ }^{11}$ Here we have something like the normativity at play in my notion of categorical norms in mind. If this is plausible, then the open question certainly does seem to raise an issue about the normativity of the epistemic "ought". However, if it is plausible, this is at least partly because the question remains too vague. In particular, we need to specify whether the pro tanto "ought" (or, if you like, the pro tanto normative reason) at issue is epistemic, or moral, or aesthetic, or what. And that will lead to problems. On one hand, if the question employs an epistemic pro tanto "ought", then it again seems false that the question is coherent after all. Consider:

- "Sure, I epistemically ought to $\Phi$, but ought I, in the sense of having a pro tanto epistemic reason, to $\Phi ? ”$

On the other hand, if the question employs a moral, or aesthetic "ought", then the question simply seems irrelevant to the issue of the normativity of the epistemic "ought". Consider:

- "Sure, I epistemically ought to $\Phi$, but ought I, in the sense of having a pro tanto moral reason, to $\Phi ? "$

Surely claims about the normativity of the epistemic "ought" cannot rest on the fact that one can coherently pose this question.

\footnotetext{
${ }^{11}$ Thanks to an anonymous referee for this suggestion.
} 
How else to distinguish the epistemic "ought" from the real "ought" in Hazlett's putatively open question? The most plausible remaining option seems to me very close to the natural one we started out with. The idea would be that we can grant that someone epistemically ought to believe that $p$, and then coherently ask whether it is the case that they ought, in some overarching deliberative sense, to believe that $\mathrm{p} .{ }^{12}$ This is indeed very close to framing the question in terms of an all-things-considered "ought", which we've seen Hazlett explicitly denies doing. But it is importantly different. Let me briefly explain.

As I see things, the all-things-considered "ought" has two importantly different dimensions, or axes. On one hand, the all-things-considered "ought" contrasts with pro tanto "ought"s. But on another, it contrasts with "ought"s of a specific domain, such as the moral, aesthetic, or epistemic domain. This is to be expected, given that the all-thingsconsidered "ought" settles the question of what one ought to do once all "ought"s have properly been taken into consideration. But put differently, then, the all-things-considered "ought" is also simply the last thing we could mean when asking whether one "really" ought to do something, or whether they ought do something in any way. After all, I have just explained the problem of filling out the putative open question with epistemic, or moral "ought"s. In this latter sense, then, the overarching deliberative "ought" and the allthings-considered "ought" are one and the same thing.

So, Hazlett seems committed to claiming that epistemic discourse is not normative because it does not settle, or even really contribute to, the question of what one

\footnotetext{
${ }^{12}$ Schroeder (2011), Wedgwood (2006), and Williams (1981) all use the term "deliberative ought".
} 
ought to $d o$ (in some broad enough sense of "do" that includes belief formation).

Understood in this way, the putatively open question does seem coherent, relatively clear, and thereby to raise an issue about the normativity of the epistemic "ought". While I think Hazlett is right that epistemic discourse is not normative in this way, I want to argue that the reverse open question argument nevertheless fails to adequately address the issue of the seemingly binding nature of epistemic evaluation.

To see why, we simply need to emphasize that overarching deliberative "ought"s and categorical "oughts" are not one and the same thing. We can do this in the following way. Consider two actions which, for the sake of argument, we will assume one categorically ought to do, but which conflict. For example:

Sandra believes she ought to give part of her salary to charity. She also believes she ought to save for her daughter's education. She doesn't have much extra cash. Ought she give part of her salary to charity? Ought she save for her daughter's education?

This scenario is consistent with the possibility of a further normative question. Namely, there is a question here about what she, in some overarching deliberative sense, ought to do. While normative dilemmas may be possible, in such a scenario it seems clear that there can be one thing Sandra really ought to do-whatever it is, perhaps it will be a function of weighing up these opposing categorical normative considerations. Notice, then, in light of this, we can see that categorical "ought"s and overarching deliberative "ought"s are different beasts. There could not be two instances of the first type of "ought", and only one of the second, if these were identical "ought"s. Note that the 
assumption that these "ought"s are categorical is not unfair in this context. This is because this assumption is only needed to point out that categorical "ought"s-whether there really are true categorical "ought"s, or not—and overarching deliberative "ought"s are not one and the same thing. The example is not intended as any kind of argument for the existence of categoricity. So, it is fair to assume, hypothetically, that the "ought"s in this example are categorical. To be sure, it may be the case that some over-arching deliberative "ought"s are also categorical; but the example serves my purposes so long as it highlights that being a categorical "ought" is not sufficient for being an overarching deliberative "ought".

For this reason, the reverse open question argument does not really speak to the issue of the seemingly binding nature of epistemic evaluation. Rather, it shows us that epistemic evaluation is not normative in a way that opponents of convention-relativism will be likely to agree with. So, I think Hazlett's reverse open question argument ultimately falls short as a defense of convention-relativism vis-à-vis one of conventionrelativism's controversial upshots. ${ }^{13}$ Moreover, as we've seen, Hazlett's distinction between inescapable and instrumental norms also fails to speak to the issue of the seemingly binding nature of epistemic evaluation. This leaves us with an important question. Why think, more precisely, that categoricity is something Hazlett should be

\footnotetext{
${ }^{13}$ The reverse open question argument seems to imply that even moral discourse isn't normative. For example, it seems coherent to ask, "I morally ought to give everything I own to charity, but ought I give everything I own to charity?". One might think this alone is a serious problem for the reverse open question argument, in the sense that the argument overgeneralizes. But I wish to remain neutral on this question. For one thing, I don't want to get into a debate about whether utterances in the moral case are incoherent. But also, it seems likely to me that Hazlett would simply be prepared to accept that his argument generalizes in this way. Thanks to [removed], [removed], and an anonymous referee for suggestions here.
} 
able to explain away or account for in the first place? Why think epistemic evaluation is categorical? This is a big question. Considering it in detail would make this a different sort of paper. That said, there are a few significant enough points I can make without having to settle that question.

\section{Anti-Realist Options}

First, regardless of whether it is true that epistemic evaluation is categorical, it is a prominent view in contemporary epistemology. Indeed, it is arguably the most natural starting point. ${ }^{14}$ That is precisely why recent attempts at casting epistemic normativity in instrumentalist terms are interesting and surprising. ${ }^{15}$ They would not seem interesting and surprising if they did not conflict with, or stand in some kind of tension with, a natural starting point. Rather, we'd just think they were obviously true. This generates a dialectical burden on a view that rejects categoricity. That is to say, rejecting categoricity is not a non-controversial option that can simply be assumed in one's theory.

Second, and more importantly, Hazlett's main anti-realist competitor, epistemic expressivism, is consistent with categorical norms. Expressivism and conventionrelativism are both views about epistemic discourse. They are meta-epistemological

\footnotetext{
${ }^{14}$ Kelly (2003) brings this out nicely. He uses cases in which it is clear that an agent epistemically ought to believe that $\mathrm{p}$, but in which the agent has no aim or desire to believe truly that $\mathrm{p}$ (in one case, the agent has an aim or desire not to believe truly that $\mathrm{p}$ ). Of course, the cases raise issues about how exactly to understand epistemic instrumentalism. For example, is it a view about the relationship between epistemic normativity and the aims or desires of agents, or is it a view about the relationship between epistemic normativity and the aim (or perhaps function) of the mental state of belief? This is a controversial and complex issue. I do not need to get into here. I simply note that responding to Kelly's straightforward objection would seem to require entering into this complex debate.

${ }^{15}$ A widely cited attempt is Steglich-Petersen (2011).
} 
views. But the way in which each of these meta-epistemological views is consistent with anti-realism is different. Expressivism is silent on the nature of the norms or standards agents express beliefs about when they utter sentences such as " $\mathrm{S}$ is justified in believing that p". Given how I have articulated categorical norms, if some epistemic norm EN is categorical, this amounts to the claim that:

EN gives you a reason to $\Phi$, regardless of your aims or desires.

This is a substantive epistemic claim. Epistemic expressivism only makes descriptive claims about what it is in virtue of which this sentence means what it does. That is to say, as a theory about the meaning of epistemic discourse, it is not committed one way or the other to substantive epistemic claims. ${ }^{16}$

\footnotetext{
${ }^{16}$ Compare the widely discussed issue of whether moral expressivism entails that morality is in some sense mind-dependent. Blackburn (1993) notably responds to this worry in roughly the following way. First, he claims that it is helpful to frame the question of whether a particular theory is committed to the minddependence of morality in terms of whether or not the theory is committed to counterfactuals of the following form (where ' $\mathrm{X}$ ' stands for an object of evaluation and ' $\mathrm{M}$ ' for a moral predicate):
}

i) If we had thought that $\mathrm{x}$ is $\mathrm{M}$, then $\mathrm{x}$ would have been $\mathrm{M}$.

ii) If we had not thought that $\mathrm{x}$ is $\mathrm{M}$, then $\mathrm{x}$ would not have been $\mathrm{M}$.

Once we have framed the question of mind-dependence in terms of whether a theory is committed to i) or ii), then we can ask, first, whether i) and ii) are moral sentences or meta-ethical (and thus descriptive) sentences. If the former, then, as Blackburn argues, expressivism is not committed to anything one way or the other, since it is not in the business of making moral statements; rather, it is in the business of making descriptive statements about our moral thought and talk. If the latter, then objections concerning expressivism's supposed commitment to the mind-dependence of morality arguably falter for other reasons. For example, as Köhler (2014) and Schroeder (2014) have pointed out, it is difficult to level this objection without saddling the expressivist with commitments the expressivist herself rejects. Detailed discussion would take us too far afield. 
Meanwhile convention-relativism is not silent on the nature of epistemic norms or standards. Recall, convention-relativism differs with respect to the second part of expressivism's semantic set-up. Again, according to convention-relativism, an agent can positively epistemically evaluate a belief, an argument, or someone's method of inquiry, without thereby valuing (expressing an attitude of acceptance towards) the central organizing value of the critical domain of the epistemic. This is plausible precisely insofar as the central organizing value of epistemology is merely conventional. So, convention-relativism is committed to the further point that the types of standards at play are conventional. According to Hazlett, this latter feature is what makes conventionrelativism about epistemic discourse consistent with anti-realism.

Of course, Hazlett thinks that the expressivist's commitment to building an attitude of acceptance into the semantics of epistemic discourse is a liability for expressivism. He seems to think it is a liability insofar as it commits the epistemic expressivist to the idea that epistemic discourse is normative in a way that he has argued it is not-namely, in the overarching deliberative sense. But - to return to the issue I flagged when introducing expressivism above - it is far from clear that this is the case. In particular, there are importantly different attitudes of acceptance available to the expressivist, and according to what strikes me as a more prominent — and plausibleapproach, the expressivist is not committed to a view about the normativity of epistemic discourse that Hazlett thinks we should reject. Let me explain.

Many expressivists take a cue from Edward Craig's story about the point or function of epistemic concepts like justification and knowledge within an informationgathering and -distributing economy such as ours (see Chrisman 2007, p.251; Chrisman 
2012, p.2; Gibbard 2003, Ch.11). On Craig's account, very roughly, when we say that someone knows that p, we "flag" that person as a "reliable informant" (Craig 1990, p.1117). In line with this, expressivists often cash out the relevant notion of norm acceptance in their semantics for epistemic evaluation in the following sort of way. They claim that utterances of the form "S knows that p", or "S is justified in believing that p", mean what they do in part by expressing some kind of non-representational attitude that is partially constituted by the utterer's disposition to rely on p's being the case in future deliberation. I think this suggests an important distinction between two types of norm acceptance. To put it one way, on one hand, we can talk about a kind of engaged acceptance, where this is linked to motivation and may indeed imply that the agent values the relevant norms or standards (in the way that Hazlett seems to assume norm acceptance entails). But on the other hand, we can talk about pragmatic acceptance, where this is merely linked to an agent's plans regarding future deliberation. This strikes me as a less engaged sort of acceptance. In particular it does not seem necessary, or even plausible, to characterize this sort of acceptance in terms of an agent valuing a set of standards (or states that the relevant standards govern). Does this point about the attitude of pragmatic acceptance imply that epistemic judgment is merely a kind of pragmatic judgment $?^{17}$ I don't think so. Recall that, according to the expressivist, utterances such as "S knows that p" also mean what they do in virtue of expressing the agent's belief that S complies with a certain set of epistemic standards. The cognitive component of the expressivist's semantics can thus help demarcate epistemic discourse as distinctively epistemic, even when the non-cognitive component is understood along the lines of an attitude of

\footnotetext{
${ }^{17}$ Thanks to an anonymous referee for pressing this point.
} 
pragmatic acceptance. Nevertheless, the mere fact that an agent is disposed to rely on something's being the case says nothing about whether or not the agent values anything in a way Hazlett would find problematic.

Importantly, this way of cashing out the relevant attitude of acceptance does not seem to be in conflict with Hazlett's reverse open question argument. Namely, it seems compatible with the supposed datum that one can coherently ask, "Sure, I epistemically ought to believe that $\mathrm{p}$, but ought I really (in the overarching deliberative sense) believe that $\mathrm{p}$ ?" After all, the first part of this question — on a properly nuanced expressivist semantics - merely expresses an attitude partially constituted by one's disposition to rely on its being the case that $p$. This is not incompatible with the further question of whether one ought, in some overarching deliberative sense, believe that $p$. As such, pragmatic acceptance seems appropriate for filling out the semantics of epistemic judgments in a way that even Hazlett would be unlikely to have problems with. ${ }^{18}$

The idea that we sometimes make epistemic evaluations without valuing the fundamental organizing value of the epistemic domain is something Hazlett thinks is an important datum to capture in our meta-epistemological theorizing. Whether or not he's right about that, it seems expressivism is no less well positioned than conventionrelativism on this score. It might seem as though I am simply affirming Hazlett's position on this issue. I am not. Rather, my point is that expressivism need not be interpreted in the way Hazlett does when comparing it with convention-relativism. More specifically, on a more plausible way of spelling out the second component of the expressivist's

\footnotetext{
${ }^{18} \mathrm{We}$ can now put the concern I flagged at the end of Section 2 in the following way. In his discussion of expressivism, Hazlett seems to illicitly jump from talk of "acceptance" (2013, p.254) to what I am calling the more specific notion of engaged acceptance (2013, p.257).
} 
semantics for epistemic discourse, we need not commit the expressivist to a view about the normativity of epistemic discourse that Hazlett rejects. ${ }^{19}$

\section{Conclusion}

Imagine you want to be an anti-realist and you have two ways of doing so. One way forces you to deny a very natural-seeming feature of epistemic discourse, and the other does not. It seems you should choose the first way. To be sure, there are many other respects in which expressivism and convention-relativism could be compared. But the point here isn't to compare expressivism and convention-relativism in a general way. Moreover, given that Hazlett argues he's offering a new and better alternative to the most prominent anti-realist view, it seems making further comparisons is his job, not ours. While convention-relativism about epistemic discourse is an important contribution to the under-explored field of meta-epistemology_one that deserves more attention than it currently receives — in the end I've argued that Hazlett owes us more of a story about why his view is an attractive alternative form of anti-realism.

\section{References}

Berker, S. 2013. Epistemic teleology and the separateness of propositions. Philosophical Review 122: 337-93.

Blackburn, S. 1993. Essays in Quasi-Realism. OUP: Oxford.

\footnotetext{
${ }^{19}$ It is worth noting that making use of "engaged" acceptance will likely seem unproblematic to many readers in the first place. I employ this distinction primarily in an attempt to make the dialectical advantage of expressivism over convention-relativism seem as strong as possible, in the sense of showing that it can do everything that Hazlett seems to think it should be able to do, and more.
} 
Boghossian, P. 2006. Fear of Knowledge: Against Relativism and Constructivism. OUP:

Oxford.

Chrisman, M. 2007. From epistemic contextualism to epistemic expressivism.

Philosophical Studies 135: 225-54.

2012. Epistemic expressivism. Philosophy Compass 7: 118-126.

Hazlett, A. 2013. A Luxury of the Understanding. OUP: Oxford.

2014. Expressivism and convention-relativism about epistemic discourse. In Fairweather, A. and Flanagan, O. (eds.) Naturalizing Epistemic Virtue. CUP: Cambridge.

Foot, P. 1972. Morality as a system of categorical imperatives. Philosophical Review 81: $305-16$.

Gibbard, A. 2003. Thinking How to Live. Harvard University Press.

Grimm, S. 2009. Epistemic normativity. In Haddock, A., Millar, A., and Pritchard, D. (eds.) Epistemic Value, pp. 243-64. OUP: Oxford.

Kelly, T. 2003. Epistemic rationality as instrumental rationality: a critique. Philosophy and Phenomenological Research 66: 612-40.

Köhler, S. 2014. Expressivism and mind-dependence: distinct existences. Journal of Moral Philosophy 11: 750-764.

Lewis, D. 1969. Convention: A Philosophical Study. Harvard University Press. 
Ridge, M. 2007. Epistemology for ecumenical expressivists. Aristotelian Society Supplementary Volume 81:82-108.

Schroeder, M. 2011. Ought, agents, and actions. Philosophical Review 120:1-41.

2014. Does expressivism have subjectivist consequences? Philosophical Perspectives 28: 278-290.

Sosa, E. 2007. A Virtue Epistemology: Apt Belief and Reflective Knowledge, vol.1. OUP: Oxford.

Steglich-Petersen, A. 2011. How to be a teleologist about epistemic reasons. In, A. Steglich-Petersen and A. Reisner (eds.), Reasons for Belief. CUP: Cambridge.

Sylvan, K. forthcoming. Epistemic reasons I: normativity. Philosophy Compass.

Wedgwood, R. 2006. The meaning of 'ought'. In, R. Schafer-Landau (ed.), Oxford Studies in Metaethics, Vol. Clarendon Press.

Williams, B. 1981. Moral Luck. Cambridge University Press.

Williamson, T. forthcoming. Justifications, excuses, and sceptical scenarios. In, F. Dorsch and J. Dutant (eds.), The New Evil Demon. OUP 